\title{
Study on the Impact of Industrial Informatization on Economic Growth
}

\author{
Jingying $\mathrm{Zhu}^{1, *}$ \\ ${ }^{1}$ Management Science and engineering,Lanzhou University of Technology,Lanzhou,China
}

\begin{abstract}
Based on the basic regression model, this paper analyzes the impact of industrial informatization on China' s economic growth. The research shows that industrial informatization has a significant positive impact on China' s economic growth. Then, considering the significant differences in the development of industrial informatization in different regions of China, the paper further explores the regional heterogeneity of industrial informatization on economic growth. The results show that there are significant differences in the impact of industrial informatization on economic growth in the three major regions of East, Central and West. That is, industrial informatization has the strongest effect on promoting economic growth in the eastern region, followed by the central region, and industrial informatization has the weakest effect on promoting economic growth in the western region.
\end{abstract}

\section{Introduction}

In order to fully grasp the opportunity of the new round of industrial revolution, China is actively promoting the development of industrial informatization and boosting China's economic growth. Industrial informatization is based on artificial intelligence and other intelligent technology development, and industrial informatization is the result of technological progress. Industrial informatization plays a key role in the promotion of economic growth ${ }^{[1]}$. However, the development of East, Middle and West regions in China is not balanced, and there are significant differences in the level of industrial informatization development in different regions.

\section{Literature Review}

With the development of industrial informatization, many researches have proved that the following methods can promote the development of Economy: first, enterprises can realize the automation of complex tasks through intelligent technology, replace labor with cheaper capital, and improve their productivityt ${ }^{[2]}$. Second, intelligent technology can realize man-machine cooperation to assist workers to work, through autonomous control to achieve production, management of intelligence, thus improving labor productivity ${ }^{[3]}$. Thirdly, intelligent technology can promote technological innovation and apply it to various industries to improve total factor production ${ }^{[4-5]}$. However, China's regional development is not balanced, and few scholars have studied whether there are differences in the influence of industrial informatization on regional economic growth. Therefore, this paper first constructs the multivariate basic panel regression model of industrial informatization affecting China's economic growth, explores the impact of industrial informatization on economic growth, and further uses the econometric model on this basis, research on regional heterogeneity of industrial informatization affecting economic growth in China.

\section{Measurement model setup and variable description}

\section{1 model setting}

Based on the theoretical model and the research of some scholars, the cost of living, the upgrading of industrial structure, the degree of economic opening and the level of urbanization are also important factors affecting economic growth, so these variables are included in the control variables. This sets the measurement model as follows:

$$
\ln \mathrm{PGDP}_{\mathrm{i}, \mathrm{t}}=\mathrm{C}+\beta_{1} \ln (\mathrm{INT})_{\mathrm{i}, \mathrm{t}}+\beta_{2} \ln (\mathrm{CH})_{\mathrm{i}, \mathrm{t}}+\beta_{3} \ln (\mathrm{SR})_{\mathrm{i}, \mathrm{t}}+\beta_{5} \ln (\mathrm{TRA})_{\mathrm{i}, \mathrm{t}}+\beta_{6} \ln (\mathrm{UR})_{\mathrm{i}, \mathrm{t}}++\mu_{\mathrm{i}, \mathrm{t}}
$$

*Corresponding author: 1060969656@qq.com 
In formula (1), " $\mathrm{t}$ " means region, "i" means time, "PGDP" means economic development, "INT" means industrial informatization, " $\mathrm{CH}$ " means cost of living, "SR" means industrial structure upgrading, "TRA" means economic openness, "UR" means urbanization, " $\mu$ " means random disturbance.

\section{2 variable description}

Economic Growth (PGDP) is chosen as the explanatory variable, and GDP per capita is used as the standard.

This paper selects industrial informatization (INT) as the core explanatory variable. This paper draws on the multi-index system of industrial informatization constructed by Zao Sun and Yulin Hou for reference to construct the index of industrial informatization from three aspects of infrastructure construction, production application, competitiveness and benefits. This index can reflect the process of industrial informatization more scientifically and reasonably. The connotations and measurement methods of each secondary indicator are as follows:(1) Software popularization and application. The income from products using basic software, supporting software, and embedded application software accounted for the percentage of the main business income of all industrial enterprises. (2) Input of intelligent equipment. The import value of selected computers, electronic components and equipment, etc. accounted for the proportion of the main business income of all industrial enterprises. (3) The ability to collect information resources. The level of Internet development in each province is used to measure the proportion of the number of Internet users in the population aged 15-64. (4) Data processing and storage capacity. It is measured by the proportion of information technology consulting service income and data processing and operation service income in the main business income of all industrial enterprises. (5) Intelligent manufacturing enterprises. The main business income of intelligent manufacturing enterprises in each province is used to represent the proportion of the main business income of national intelligent manufacturing enterprises. Among them, intelligent manufacturing-related enterprises refer to the ten major areas mentioned in "Made in China 2025" and obtain relevant data through WIND database. (6) New product production. The measurement of the proportion of the sales income of new products in the main business income of industrial enterprises. (7) Platform operation and maintenance. Including the operation and maintenance of online information platforms, e-commerce platforms, and logistics management platforms, measured by the proportion of the income from platform operation and maintenance services in each province and region to the main business income of all industrial enterprises. This data is included in the information system integration business income. (8) Innovative ability. The ratio of the number of national patent applications granted to the fulltime equivalent of R\&D personnel is used. (9) Economic benefits. Use the total asset contribution rate and cost utilization rate of each province to express. (10) Social benefits. Measured by the energy consumption per unit GDP of each province, including electricity and coal. Industrial intelligence is synthesized by the above 10 secondary indicators using the coefficient of variation method.

Cost of living $(\mathrm{CH})$, industrial structure upgrading (SR), economic openness (TRA) and urbanization level (UR) are selected as control variables. The cost of living is measured by the proportion of per capita consumption expenditure (including housing expenditure) of urban households in each province as disposable income, and industrial structure upgrading is expressed by the proportion of regional tertiary sector of the economy value added as GDP The degree of economic openness is expressed by the proportion of the total import and export to the GDP of each region, and the level of urbanization is measured by the proportion of the urban population to the total population.

\subsection{Measurement methods of industrial informatization}

It can be seen from 3.2 that the level of industrial informatization is measured by the coefficient of variation method. The coefficient of variation method will now be introduced.

The coefficient of variation method directly uses the information contained in the index to assign weight to the index, avoiding the bias caused by human subjective factors. The basic idea of this method is: the greater the difference in the evaluation index system, the more difficult it is to achieve. Such an index can better reflect the gap between the evaluated objects and must be given a higher weight. The specific methods are as follows:

There are $\mathrm{m}$ evaluation units and $\mathrm{n}$ evaluation indicators to form an initial data matrix:

$$
X=\left(x_{i j}\right)_{m \times n},(i=1,2, \cdots, m ; j=1,2, \cdots, n)
$$

Among them, $x_{i j}$ represents the value of the $j$-th evaluation index of the $\mathrm{i}$-th evaluation unit.

Because the detailed evaluation indicators are not all positive indicators, the various indicators are changed very poorly:

$$
\begin{aligned}
& \qquad \mathrm{x}_{\mathrm{ij}}^{\prime}=\frac{\mathrm{x}_{\mathrm{ij}}-\min _{1 \leq \mathrm{i} \leq \mathrm{m}}\left\{\mathrm{x}_{\mathrm{ij}}\right\}}{\max _{1 \leq \mathrm{i} \leq \mathrm{m}}\left\{\mathrm{x}_{\mathrm{ij}}\right\}-\min _{1 \leq \mathrm{i} \leq \mathrm{m}}\left\{\mathrm{x}_{\mathrm{ij}}\right\}} \\
& \text { Positive index: } \mathrm{x}_{\mathrm{ij}}^{\prime}=\frac{\max _{1 \leq \mathrm{i} \leq \mathrm{m}}\left\{\mathrm{x}_{\mathrm{ij}}\right\}-\mathrm{x}_{\mathrm{ij}}}{\max _{1 \leq \mathrm{i} \leq \mathrm{m}}\left\{\mathrm{x}_{\mathrm{ij}}\right\}-\min _{1 \leq \mathrm{i} \leq \mathrm{m}}\left\{\mathrm{x}_{\mathrm{ij}}\right\}}
\end{aligned}
$$

After the range change, all indicators are positive indicators.

Then determine the coefficient of variation:

$$
\mathrm{v}_{\mathrm{j}}=\frac{\sigma_{\mathrm{j}}}{\overline{\mathrm{x}_{\mathrm{j}}}}
$$


Among them

$$
\overline{x_{j}}=\frac{\sum_{i=1}^{i=m} x_{i j}^{\prime}}{m} \sigma_{j}=\sqrt{\frac{\sum_{i=1}^{m}\left(x_{i j}^{\prime}-\overline{x_{j}}\right)^{2}}{m-1}}
$$

Then determine the weight of each evaluation index:

$$
\mathrm{w}_{\mathrm{j}}=\frac{\mathrm{v}_{\mathrm{j}}}{\sum_{\mathrm{j}=1}^{\mathrm{n}} \mathrm{v}_{\mathrm{j}}}
$$

Finally, the weighted summation method is used to calculate the comprehensive score of the evaluation unit:

$$
\mathrm{s}_{\mathrm{i}}=\sum_{\mathrm{j}=1}^{\mathrm{n}} \mathrm{w}_{\mathrm{j}} \mathrm{x}_{\mathrm{ij}}^{\prime}
$$

\section{4 data sources and descriptive statistics}

The raw data involved in the above variables are from the 2005-2018 China Statistics Yearbook, China Science and Technology Statistics Yearbook, China Labor Statistics Yearbook, China Electronic Information Industry Statistics Yearbook, China Energy Statistics Yearbook and the financial statements of enterprises related to industrial informatization based on WIND database. The descriptive statistics of the data for each variable are shown in Table

\begin{tabular}{|c|c|c|c|c|c|}
\hline Variable & $\begin{array}{l}\text { Observed } \\
\text { value }\end{array}$ & Minimun & maximum & 1 mean & $\begin{array}{r}\text { standard } \\
\text { deviation }\end{array}$ \\
\hline INT & 420 & 0.030 & 0.850 & 0.199 & 0.149 \\
\hline $\mathrm{CH}$ & 420 & 59.830 & 84.180 & 70.846 & 4.885 \\
\hline SR & 420 & 28.620 & 80.980 & 43.003 & 9.240 \\
\hline $\mathrm{HI}$ & 420 & 9.790 & 28.190 & 15.870 & 2.504 \\
\hline TRA & 420 & 1.680 & 179.910 & 31.122 & 38.060 \\
\hline UR & 420 & 26.860 & 89.610 & 53.534 & 13.890 \\
\hline LNFYB & 420 & 7.440 & 22.690 & 13.191 & 2.769 \\
\hline
\end{tabular}
1:

Table 1 key variable data descriptive statistics

\section{Results analysis}

In order to make the model estimate more reliable, a Multicollinearity test should be performed before the model estimate, which may result in spurious regression if there are significant Multicollinearity between the variables. The Multicollinearity test results are shown in table 2 below, all variance inflation factors for regression variables are less than 10 , indicating that the model has passed the Multicollinearity test.

Table 2 results of regression Multicollinearity test

\begin{tabular}{ccc}
\hline Variable & VIF & 1/VIF \\
\hline INT & 3.60 & 0.278 \\
CH & 1.25 & 0.801 \\
SR & 1.90 & 0.527 \\
HI & 1.47 & 0.678 \\
TRA & 3.03 & 0.330 \\
UR & 3.32 & 0.301 \\
LNFYB & 1.28 & 0.778 \\
\hline Mean value & 2.27 & \\
\hline
\end{tabular}

Using Stata 13.1 software to carry on the regression analysis to the model (1) separately, the regression result is as follows Table 3:
Table 3 basic model regression analysis

\begin{tabular}{|c|c|c|c|}
\hline & Coefficient & Standard error & t statistics \\
\hline $\ln (\mathrm{INT})$ & $0.184 * * *$ & 0.0345 & 5.34 \\
\hline $\ln (\mathrm{CH})$ & $-2.102 * * *$ & 0.1797 & -11.69 \\
\hline $\ln (\mathrm{SR})$ & -0.076 & 0.0876 & -0.87 \\
\hline $\ln (\mathrm{TRA})$ & $-0.203^{* * *}$ & 0.0204 & -9.94 \\
\hline $\ln (\mathrm{UR})$ & $2.413^{* * *}$ & 0.0818 & 29.52 \\
\hline cons & $11.046^{* * *}$ & 0.8865 & 12.46 \\
\hline $\mathrm{N}$ & \multicolumn{3}{|c|}{0.8510} \\
\hline $\mathrm{R}^{2}$ & \multicolumn{3}{|c|}{420} \\
\hline
\end{tabular}

From Table 3, the marginal effect of industrial informatization on national economic growth is 0.184 , and industrial informatization has significant positive effect on economic growth. For every $1 \%$ increase of industrial intelligence, the average economic growth is $0.184 \%$. Therefore, the industrial informationization is the present stage our country economy growth new power.

\section{Analysis of regional heterogeneity}

According to the above research, industrial informatization can promote economic growth, but China's regional development is not balanced, and the development of industrial intelligence varies from region to region. In order to find out whether the industrial informatization has heterogeneity to the economic growth in China, the regional virtual variable is added into the model (1), and the regression results are as follows: Table 4.

Table 4 basic model regression analysis

\begin{tabular}{|c|c|c|c|}
\hline & $\begin{array}{c}\text { Eastern } \\
\text { region }\end{array}$ & $\begin{array}{c}\text { Central } \\
\text { region }\end{array}$ & $\begin{array}{c}\text { Western } \\
\text { region }\end{array}$ \\
\hline $\ln ($ INT $)$ & $0.491^{* * *}$ & $0.317^{* * *}$ & $0.086^{* *}$ \\
\hline & $(6.24)$ & $(4.20)$ & $(2.08)$ \\
\hline $\ln (\mathrm{CH})$ & $-2.818^{* * *}$ & $-2.417^{* * *}$ & $-1.674^{* * *}$ \\
\hline & $(-10.57)$ & $(-6.86)$ & $(-5.65)$ \\
\hline $\ln (\mathrm{SR})$ & $-0.669^{* * *}$ & -0.273 & 0.006 \\
\hline & $(-4.43)$ & $(-1.31)$ & $(0.03)$ \\
\hline $\ln (\mathrm{TRA})$ & $-0.401^{* * *}$ & $-0.353^{* * *}$ & $-0.092^{* *}$ \\
\hline & $(-9.25)$ & $(-4.72)$ & $(-2.53)$ \\
\hline $\ln (\mathrm{UR})$ & $2.661^{* * *}$ & $2.505^{* * *}$ & $2.657^{* * *}$ \\
\hline & $(17.13)$ & $(10.98)$ & $(25.98)$ \\
\hline $\mathrm{cons}$ & $16.537^{* * *}$ & $13.236^{* * *}$ & $7.603^{* * *}$ \\
\hline & $(13.04)$ & $(7.54)$ & $(4.71)$ \\
\hline $\mathrm{N}$ & 154 & 112 & 154 \\
\hline $\mathrm{R}^{2}$ & 0.8681 & 0.7914 & 0.8593 \\
\hline
\end{tabular}

The marginal impact on the economic growth of the east, middle and West regions is $0.491,0.317$ and 0.086 respectively, that is, for every $1 \%$ increase in industrial informatization, the industrial informatization in the eastern region will increase by $0.491 \%$, and the industrial informatization in the central region will increase by $0.317 \%$, in the western region, the industrial informatization increased by 0.086 percent. Therefore, although the industrial informatization in the eastern, central and western region has promoted the economic growth, from the perspective of the impact of the industrial informatization on the economic growth in China as well as in the eastern, Central and western region, the eastern region and the central region are stronger than the whole 
country in China, while the western region is the weakest, i. e. The marginal impact of industrial informatization on the economic growth of the eastern region is the strongest, and the central region is the second, and the whole country is the third, and the western region is the weakest. The influence of industrial informatization on economic growth has regional heterogeneity. The reason for this may be that the industrial environment and policy environment are different in different regions, and the impact of industrial informatization on economic growth will be constrained by these environmental factors, therefore, the impact of industrial informatization on economic growth varies from region to region.

\section{Conclusions and recommendations}

During the new technological revolution, it is necessary to strengthen the deep integration of real economy and artificial intelligence, which is the key way to realize the china's economic growth. This paper examines the profound impact of industrial informatization on economic growth through empirical tests. The results show that the development of industrial informatization has promoted the china's economic growth, but the impact of industrial informatization on economic growth in east, middle and West regions is heterogeneous.

Based on the conclusions of the study, the paper puts forward the following policy recommendations:

Informatization can realize the intensive transformation of China's economic development mode by promoting technical efficiency and technological progress. Therefore, it is necessary to deeply understand the significance of the new generation of information technology to China's economic development. We will strengthen the research on the basic theories of the new generation of information technology and strive to make breakthroughs in theories, methods, tools and systems, so as to promote its intelligent integration with the development of economy and society.

Strengthen the support for the development of industrial informatization and promote the quality of economic growth. The development of industrial informatization not only needs to create a good system environment, but also needs to improve the relevant supporting infrastructure construction. China should actively seize the opportunity of the new round of industrial revolution to realize the transformation of industrialization and formulate various policies and measures to promote the intelligent development of industry, for the development of industrial informatization to create a good policy soft environment and provide strong policy support. At the same time, the government should increase investment in information technology and other new infrastructure, complement the development of industrial informatization infrastructure shortage, and provide strong hardware support.

In addition, the effects of the development of industrial informatization in different regions on the intensification of economic growth are affected by informatization infrastructure and informatization talents. Local governments should devote themselves to improving their own technological basic capabilities and strengthening the intensity of investment in science and technology, especially investment in artificial intelligence-related technologies. For example: through the establishment of informatization support funds, the investment in complementary innovation and combined innovation in informatization can be increased, which will not only help consolidate the local technical foundation, achieve regional technological progress, but also achieve intensive economic growth. Leading the high-quality development in China.

\section{References}

1. Zao Sun,Yulin Hou.How does industrial informatization reshape the employment structure of the labor force[J].China Industrial Economy,vol.5,pp.61-79,2019.

2. MAKRIDAKIS S. The Forthcoming Artificial Intelligence ( $\mathrm{AI}$ ) Revolution: Its Impact on Society and Firms $[\mathrm{J}]$. Futures, 2017, 90 (6) : 46-60.

3. GRAETZ G, MICHAELS G. Robots at Work: The Impact on Productivity and Jobs[R].London: Centre for Economic Performance Discussion Paper, 2015.

4. BRYNJOLFSSON E, ROCK D, SYVERSON C. Artificial Intelligence and the Modern Productivity Paradox: A Clash of Expectations and Statistics [R]. Boston: NBER Working Paper, 2017.

5. Cai Yuezhou, Chen Nan. AI and high quality growth and high quality employment in the new technological revolution [J]. A study of quantitative economy and technical economy, 2019, 36 (5): 3-22. 